\title{
Simulation, and Design of Charger for Electric Vehicle using PV EV \& BESS
}

\author{
Mayur Padore' ${ }^{1}$ Prof. R.M. Bhombe ${ }^{2}$, Prof. Yogesh Likhar ${ }^{3}$ \\ ${ }^{1}$ Mtech Student, ${ }^{2,3}$ Professor \\ ${ }^{1,2,3}$ Department of Electrical Engineering, \\ ${ }^{1,2,3}$ Gurunanak Institute of Engineering \& Technology, Nagpur, India
}

Received on: 01 May, 2021, Revised on: 26 May 2021 , Published on: 28 May 2021

\begin{abstract}
Electric vehicle demands are also booming with the increasing energy consumption and depletion of fossil fuels. In Electric Vehicle, energy storage systems play an important role as the cost and weight of the vehicle and the reliability of the vehicle are influenced by the battery and power electronic converters used in battery charger. Various converters are used as the interface in these systems for extracting the power from the renewable sources or grid depending on the availability of renewable energy sources and feed it to the EV battery. Extensive research is going in the development of renewable energy system employing different power electronic converters for electric vehicle energy storage applications. Hence, this research work is focused on the design and development of PV array based EV battery charger with backup battery bank. This proposed system facilitates uninterruptable charging of EV battery in constant voltage charging mode irrespective of the intermittency of $P V$ array using Sepic converter and bidirectional interleaved $d c-d c$ converter. Simulation studies and experimental investigation are carried out in order to prove the efficacy of the proposed system. An improved grid integrated PV fed electric vehicle battery charging system was proposed employing a new bidirectional dc-ac converter configuration to feed the excess power generated from the PV array to the single-phase utility grid in addition to the charging of EV battery during peak sunshine hours. During low and non-sunshine hours, charging of EV battery was supported by the utility grid in this proposed system. The new bidirectional $d c-a c$ converter configuration employed in this proposed system has an added advantage of inherent self-grid synchronization capability which in turn reduces the control complexity of the proposed charging system. Aforementioned individual charging systems are integrated together to
\end{abstract}

develop grid-tied hybrid renewable energy sourcesbased EV battery charging system. An automatic controller is proposed in this charging system which helps in efficient power flow between the RES and loads depending on the power generation from the renewable energy sources. Irrespective of the intermittent nature of RES, the proposed system ensures uninterruptable charging of EV battery. Also, excess power generated from the RES is fed to the grid in this proposed system.

Keywords- Electric Vehicle battery charger, Renewable energy sources, Bidirectional interleaved dc-dc converter, Bridgeless Buck converter, Bidirectional line commutated converter, Backup battery bank.

\section{I - INTRODUCTION}

The extensive use of fossil fuels from the fast depleting conventional energy sources have increased the carbondi-oxide emission which in turn eventually leads to greenhouse gas effect [Santhosh and Govindaraju, 2017; Knez and Obrecht, 2019]. Ever increasing effects of greenhouse gases from the conventional IC engines paved to the booming of pollution free Electric Vehicle $(\mathrm{EV})$ in the automobile industry [Shukla et al., 2018].The invention of Electric vehicle starts with the invention of electric motor for small model car by Á nyos Jedlik in 1828 followed by the invention of small scale electric car powered by non-rechargable batteries in 1835 by Professor Sibrandus Stratingh from the University of Groningen, Netherlands. Later in 1990, General motors president introduced "Impact" two 


\section{International Journal of Innovations in Engineering and Science, www.ijies.net}

seater electric vehicle at Los Angeles Auto Show. The modern highway electric vehicle era started with the launch of Tesla Roadster from Tesla motors in 2008 in California followed by Mitsubishi i-MiEV in 2009 in Japan. Major automobile industries like Nissan, BMW, Renault, Ford, Volkswagen and Chevrolet competitively launched their EVs and thus, the global stocks of plug-in electric cars have reached 5.1 million units in December 2018.

Usually, traction batteries are used in electric vehicles which can handle high power and energy within a limited space and weight. Hence, extensive research is going on in the advancement of battery technology suitable for EVs [Young et al., 2013]. Formerly, Lead acid batteries are exclusively used in EVs. Low specific energy and short cycle life of lead acid batteries has reduced its use in EV and thus it was replaced by nickel batteries, which has high power density and reliability. But nickel batteries have the problem of high selfdischarge and heat generation at high temperatures. Currently, lithium batteries are preferred due to its high power density, light weight and size. It overcomes the problems of low specific energy, poor temperature characteristics and chemical leakage [Chen et al., 2012; Korth Pereira Ferraz et al., 2018]. Charging of EV battery from the utility grid increases the load demand on the grid and eventually increases the electricity bills to the EV owners which necessitate the use of alternate energy sources. Pollution free Renewable Energy Sources (RES) which are abundantly available can be used as the alternative source to charge the EV battery. Among various RES, wind and solar energy are sustainable and fast growing energy sources [Badawy et al., 2017]. Although, due to the unpredictable nature of $\mathrm{PV}$ array and wind energy, EV charger requires power electronic interfaces for charging of EV battery [Chen, 2008]. Power converters are the interfaces between RES and EV battery and it plays the major roles like extracting power from RES and controlling the power flow between RES and EV battery. During low or non availability of RES, EV chargers necessitate secondary sources like back up battery bank and grid for uninterruptable charging of EV battery. During excess power generation from the RES, back up battery bank can be charged and also power can be fed to grid. In order to accomplish these operations, there is a need for bidirectional dc-dc converter and bidirectional ac-dc converter in EV charger.

The configuration shown in Fig. 1 is the grid-connected PV-EV battery charging system [Savio et al., 2019; Fathabadi, 2017a]. This system simultaneously charges the battery and transfers the excess power from PV array to the grid during peak sunshine hours. At the same time, when the solar irradiation is low, battery can be charged from the grid. Also, during peak load demand, EV battery can support the utility grid in this configuration. Hence, a bidirectional inverter and bidirectional dc-dc converter is used in the grid-connected PV system. Bidirectional inverter acts as an inverter when the power is transferred from PV array to grid and acts as a rectifier when the power is transferred from grid to EV battery [Mesentean et al., 2010]. The basic configuration of bidirectional dc-dc converter is a two quadrant DC-DC charger [Du et al., 2010]. It acts as a buck converter during charging mode and boost converter during discharging mode. Numerous bidirectional charger topologies are reported in the literature [Du et al., 2010; Kwon et al., 2014; JiTai Han et al., 2013; Jiang et al., 2013; Mirzaei et al., 2010; Aamir and Kim, 2011; Inoue and Akagi, 2007; Xiaodong Li and Bhat, 2010; Chen et al., 2010]. These topologies are classified into isolated and non-isolated chargers which are discussed in this section.

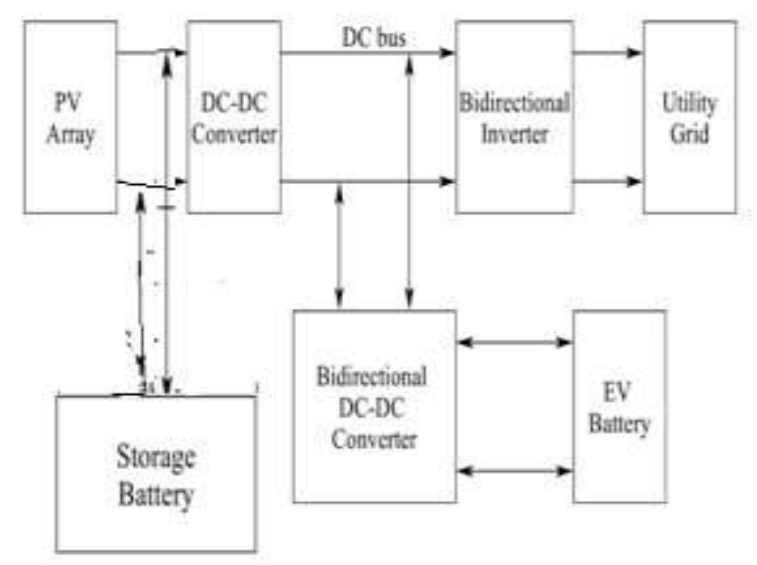

Fig. 1-Block diagram of grid connected PV-EV battery charging system

\section{II- PROPOSED SYSTEM}

In the conventional architecture of DC bus charging station with PV integration (Fig. 1a), all the three power sources, including $\mathrm{PV}$ and $\mathrm{EV}$ charger unidirectional sources, and AC grid bi-directional source, are all connected through three separate converters. The proposed DC bus charging station (Fig. 1b), consists of one more bi-directional power source BES sharing the same DC bus. The BES is utilized to maintain the DC link voltage and balance power surplus/insufficiency from the PV. With this configuration, the function and 


\section{International Journal of Innovations in Engineering and Science, www.ijies.net}

operating modes can be discussed as follows in detail.
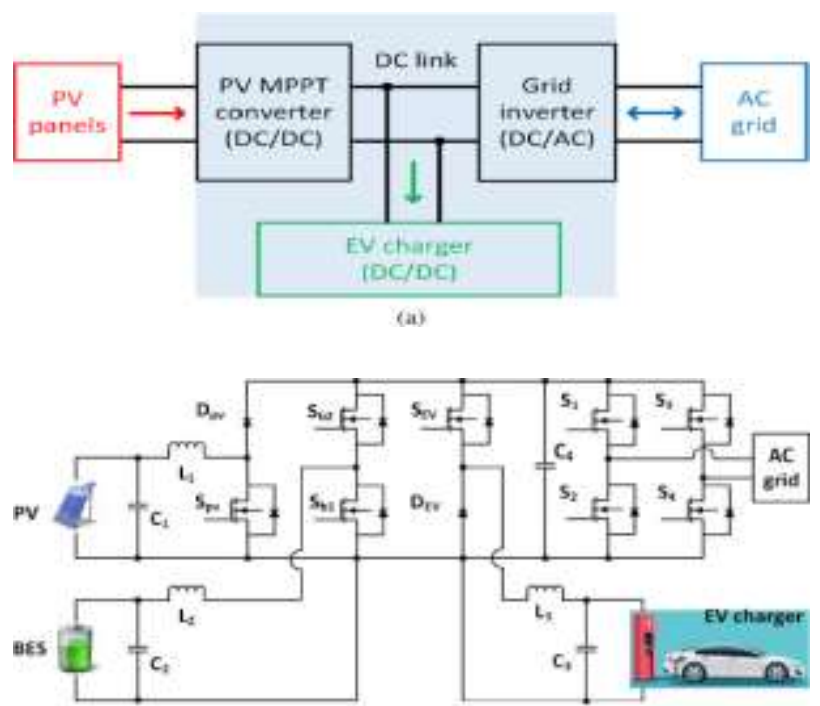

(b)

Fig 2: Multiport converter architectures, (a) the conventional architecture of EV charging stations integrated with $P V$, and (b) the proposed multiport converter based EV charging station architecture integrated with $P V$ and BES.

\section{A. $\quad$ Mode 1: PV to EV}

In this mode, the switches $\mathrm{Spv}, \mathrm{Sb} 1$, and $\mathrm{Sb} 2$ are turned off while SEV is turned on (Fig. 2a). Therefore, PV directly delivers power to the load, as shown in Fig. 2a. The differential equations in this stage can be expressed as follows:

$$
\begin{aligned}
& x_{P V}-C_{1}{ }_{d t} d t+x_{E V} \\
& C_{2} \frac{d n_{C 2}}{d t}-\frac{n_{B u t} v_{C 2}}{r_{l}} \quad \text { ir.a }
\end{aligned}
$$

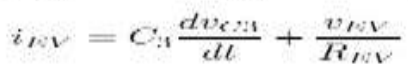

$$
\begin{aligned}
& N_{C 1}-N_{03}-T_{3}{ }^{2} d t \\
& T_{-2} \frac{i_{L 2}}{d t}-n_{C \cdot 2}
\end{aligned}
$$

where $\mathrm{C} 1, \mathrm{C} 2, \mathrm{C} 3, \mathrm{~L} 1, \mathrm{~L} 2, \mathrm{~L} 3$, and rb represent the capacitance of the PV port capacitor, the capacitance of the BES port capacitor, the capacitance of the EV port capacitor, the inductance of the PV port inductor, the inductance of the BES port inductor, the inductance of the EV load port inductor, and the equivalent resistance between vBat and C2, respectively, as shown in Fig. 1b; iPV , iEV, iL2, and iL3 represent the output current from PV panels, the current of EV load, the current through inductor L2, and the current through inductor $\mathrm{L} 3$, respectively; $\mathrm{vC} 1, \mathrm{vC} 2, \mathrm{vC} 3, \mathrm{vBat}$, and $\mathrm{vEV}$ represent the voltage across capacitor $\mathrm{C} 1$, the voltage across $\mathrm{C} 2$, the voltage across $\mathrm{C} 3$, output voltage from

BES, and the charger voltage, respectively. The duty cycle for the switch Spv can be obtained with:

$$
\frac{V_{D C}}{V_{P V}}=\frac{1}{1-D_{p v}}
$$

where VDC, VPV, and Dpv represent the DC link voltage, voltage of PV array, and duty cycle of switch Spv, respectively.

B.

$$
\begin{gathered}
\text { Mode 2: BES to EV } \\
i_{P V}=C_{1} \frac{d v_{C 1}}{d l} \\
L_{2} \frac{i_{L_{2}}}{d t}-v_{D C}-v_{C 2} \\
v_{D O}-v_{C 3}=L_{3} \frac{i_{L_{3}}}{d t} \\
C_{2} \frac{d v_{C 2}}{d t}=\frac{v_{B a t}-v_{C 2}}{r_{b}}-i_{L_{2}} \\
i_{F V}=C_{3} \frac{d v_{C 3}}{d t}+\frac{v_{E V}}{R_{E V}}
\end{gathered}
$$

When Spv and SEV are turned on while Sb1 and Sb2 are turned off, BES is discharged to the EV load, as shown in Fig. 2b. The differential equations in this mode can be expressed as follows:

where vDC refers to DC link voltage, which equals to the voltage across capacitor $\mathrm{C} 4$. The duty cycle for switch $\mathrm{Sb} 1$ can be obtained with

$V_{D C} \quad 1$

$V_{\text {Hith }} \quad 1 \quad D_{b 1}$

where VDC, VBat, and Db1 represent the DC link voltage, voltage of BES, and duty cycle of switch Sb1, respectively.

\section{C. $\quad$ Mode 3: PV to BES}

When $\mathrm{Sb} 2$ is turned on while Sb1, Spv and SEV are turned off, BES is charged from the PV surplus energy, as shown in Fig. 2c. The differential equations in this mode can be expressed as follows

$$
\begin{gathered}
i_{P V}=C_{1} \frac{d v_{C 1}}{d t}-i_{L 2} \\
I_{2} \frac{i_{L 2}}{d t}=v_{C 1}+v_{D O}-v_{C 2} \\
I_{S 3} \frac{i_{L 3}}{d t}=v_{D O}-v_{C S} \\
C_{2} \frac{d v_{C 2}}{d t}=\frac{v_{B D t}-v_{C 2}}{r_{b}}-i_{T 2} \\
i_{E V}=C_{3} \frac{d v_{C H}}{d t}+\frac{v_{E V}}{R_{F V}}
\end{gathered}
$$




\section{International Journal of Innovations in Engineering and Science, www.ijies.net}

The duty cycle for the switch Sb2 can be obtained with:

$$
\frac{V_{B a t}}{V_{D C}}=D_{b 2}
$$

where Db2 represents the duty cycle of the switch Sb2.

D. Other Modes: PV to BES, Grid to EV, and PV to Grid The operating principle of other modes including $\mathrm{PV}$ to BES, grid to EV, and PV to grid. Besides, the differential equations can be similarly expressed with the same analysis method in Modes 1 to 3 . The detailed simulation analysis will be provided in the following section.

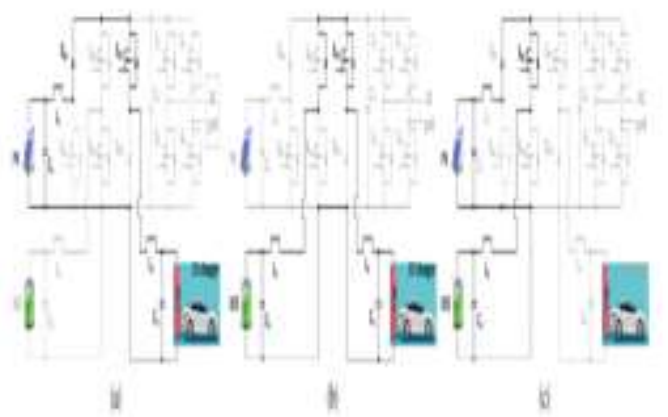

Fig.3: Multiport converter operating modes, (a) PV supplies EV charging when solar energy is sufficient, (b) BES supplies EV charging during PV intermittent, and (c) PV charges BES when solar generation is surplus.

\section{III- SIMULATION RESULTS}

\section{CASE-1: EV CHARGING:}

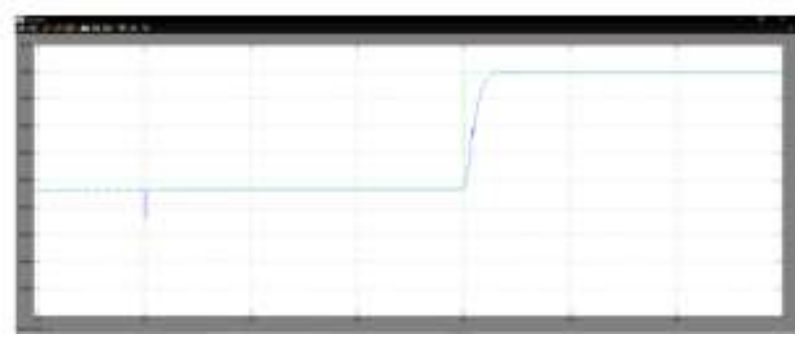

(a) Demand and consumed power of EV charging.

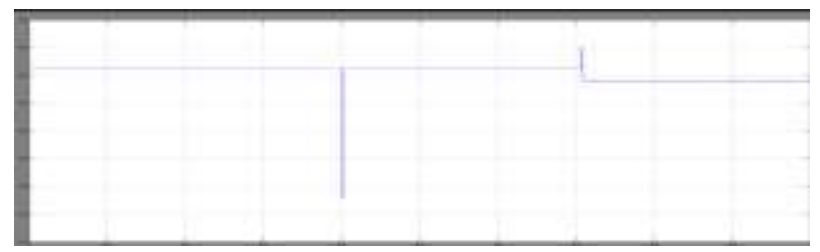

(b) Terminal voltage of the EV charger.

Fig.4: The simulation results of EV charging
The control scheme is simulated with

MATLAB/Simulink. At $0.4 \mathrm{~ms}$ of the simulation time, the irradiance drops from $700 \mathrm{k} / \mathrm{W} 2$ to $600 \mathrm{k} / \mathrm{W} 2$, and at $0.7 \mathrm{~ms}$ of the simulation time, the load should be varied. At $700 \mathrm{~ms}$ of the simulation time, EV charging demand suddenly goes up from $5.7 \mathrm{~kW}$ to $7.7 \mathrm{~kW}$; it can be seen in Fig. 3.

\section{CASE:2- BATTERY ENERGY STORAGE:}

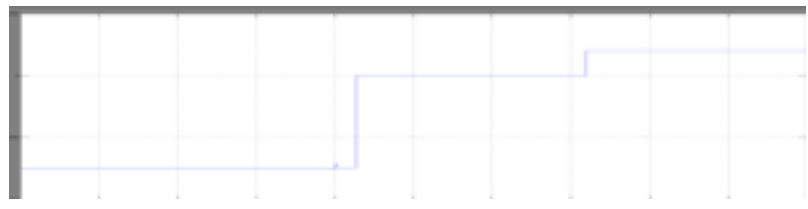

(a) Output power from BES.

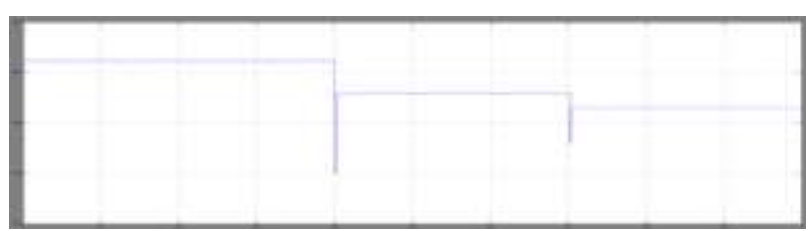

(b) Terminal voltage of the BES. Fig.4: The simulation results of the BES.

Fig.5: The simulation results of the BES.

In this case, between the simulation time of 0 to $0.4 \mathrm{~ms}$, the EV charging demand is low while the PV generation is sufficient. Therefore, both PV-to-EV and PV-to-BES modes are triggered, and the surplus PV generation charges the BES. Between the simulation time of $0.4 \mathrm{~ms}$ to $0.7 \mathrm{~ms}$, the $\mathrm{PV}$ panels can provide $5.7 \mathrm{~kW}$ which meets the EV charging amount. As a result, the system is operated in PV-to-EV mode and no BES charging/discharging is required. After the charging demand increase at $0.7 \mathrm{~ms}$, the PV panels are not able to supply all the required $7.7 \mathrm{~kW}$ charging power under the condition of $400 \mathrm{k} / \mathrm{W} 2$ irradiance. Therefore, the BES starts to discharge and supply EV charging with $2 \mathrm{~kW}$ and provides voltage support, as shown in Fig. 4

\section{IV- CONCLUSION}

The proposed system is designed and simulated in Simulink environment of the MATLAB software and the results are furnished for the different modes of operation. The simulation results emphasize the effectuality of the proposed charger.In this research work, an efficient stand-alone PV array based off-board EV battery charging system with additional storage battery bank is designed and developed. In order to feed excess power 


\section{International Journal of Innovations in Engineering and Science, www.ijies.net}

generated from PV array to grid and also to support the charging of EV battery from grid during low and nonsunshine hours, an enhanced grid connected PV-EV battery charging system is designed. The proposed system is designed to charge an EV battery in the standalone mode or grid connected mode depending on the power generation from the renewable energy sources. In this improved charging system, PV array \& Battery are used as the primary sources for charging EV battery \& the backup battery and utility grid are used as secondary sources during low or insufficient power generation from the renewable energy sources. Utility grid is also integrated with the proposed system through the proposed bidirectional line commutated converter. Simulation studies and experimental investigation of individual charging systems are carried out and the comparison results between existing and the proposed charger Stand-alone PV array fed EV battery charging system is designed and fabricated bidirectional interleaved dc-dc converter. This charger employs backup battery bank to charge the EV battery during low and non-sunshine hours. Also, this backup battery bank is charged apart from charging of EV battery during peak sunshine hours. Thus, the proposed system charges the EV battery in constant voltage charging mode irrespective of the PV array irradiation conditions. The dynamic response of the proposed charger in simulation studies and experimental investigation validate the performance of the system. The efficacy of the proposed charger is proved from the comparative analysis results between the existing and proposed charger with better performance and efficiency in all the modes of operation.

\section{V- REFERENCES}

[1] I. Santhosh, T. K. and Govindaraju, C. [2017], 'Dual input dual output power converter with one-step-ahead control for hybrid electric vehicle applications', IET Electrical Systems in Transportation 7(3), 190 - 200.

[2] Shariful Islam, M., Mithulananthan, N. and Quoc Hung, D. [2019], 'Coordinated EV charging for correlated EV and grid loads and PV output using a novel, correlated, probabilistic model', International Journal of Electrical Power and Energy Systems 104(July 2018), 335-348.

[3] Knez, M. and Obrecht, M. [2019], 'A review of available chargers for electric vehicles : United States of America, European Union, and Asia Plug in Hybrid Vehicles Society of Automotive Engineers, Renewable and Sustainable Energy Reviews 109, 284-
293.

[4] Young, K., Wang, C., Wang, L. Y. and Strunz, K. [2013], Electric Vehicle Battery Technologies, in 'Electric Vehicle Integration into Modern Power Networks', Springer New York, New York, NY, pp. 1556

[5] Chen, X., Shen, W., Vo, T. T., Cao, Z. and Kapoor, A. [2012], An overview of lithium-ion batteries for electric vehicles, in '2012 10th International Power \& Energy Conference (IPEC)', IEEE, pp. 230-235.

[6] Farzin, H., Member, S. and Fotuhi-firuzabad, M. [2016], 'A Practical Scheme to Involve Degradation Cost of Lithium-Ion Batteries in Vehicle-to-Grid Applications', IEEE Transactions on Sustainable Energy 7(4), 1730-1738.

[7] Xiaodong Li and Bhat, A. K. S. [2010], 'Analysis and Design of High-Frequency Isolated Dual-Bridge Series Resonant DC/DC Converter', IEEE Transactions on Power Electronics 25(4), 850-862.

[8] Badawy, M. O., Member, S., Sozer, Y. and Member, S. [2017], 'Power Flow Management of a Grid Tied PVBattery System for Electric Vehicles Charging', IEEE Transactions on Industry Applications 53(2), 1347 1357.

[9] Du, Y., Zhou, X., Bai, S., Lukic, S. and Huang, A. [2010], Review of Non-isolated Bi-directional DC-DC Converters for Plug-in Hybrid Electric Vehicle Charge Station Application at Municipal Parking Decks, in '2010 Twenty-Fifth Annual IEEE Applied Power Electronics Conference and Exposition (APEC)', pp. 1145-1151.

[10] Fathabadi, H. [2017a], 'Novel grid-connected solar/wind powered electric vehicle charging station with vehicle-to-grid technology', Energy 132, 1-11.

[11] Fathabadi, H. [2017b], 'Novel wind powered electric vehicle charging station with vehicle-to-grid (V2G) connection capability', Energy Conversion and Management 136, 229-239.

[12] Savio, D. A., Juliet, V. A., Chokkalingam, B., Padmanaban, S., Holm-nielsen, J. B. and Blaabjerg, F. [2019], 'Photovoltaic Integrated Hybrid Microgrid Structured Electric Vehicle Charging Station and Its Energy Management Approach', Energies 12, 1-28.

[13] Inoue, S. and Akagi, H. [2007], 'A Bidirectional DCDC Converter for an Energy Storage System With Galvanic Isolation', IEEE Transactions on Power Electronics 22(6), 2299-2306.

[14] Jang, Y. and Jovanovic, M. M. [2009], 'A Bridgeless PFC Boost Rectifier With Optimized Magnetic Utilization', IEEE Transaction on power Electronics 
Vol. 6, No. 4, 2021, PP. 12 -17

\section{International Journal of Innovations in Engineering and Science, www.ijies.net}

24(1), 85-93.

[15] Aamir, M. and Kim, H. [2011], Analysis of ZVS nonisolated bidirectional DC-DC converter, in '2011 IEEE 54th International Midwest Symposium on Circuits and Systems (MWSCAS)', pp. 1-4.

[16] JiTai Han, Chang-Soon Lim, Ja-Hwi Cho, Kim, R.-y. and Hyun, D.-s. [2013], A high efficiency non-isolated bidirectional DC-DC converter with zero-voltagetransition, in 'IECON 2013 - 39th Annual Conference of the IEEE Industrial Electronics Society', IEEE, pp. $198-203$

[17] Kwon, M., Oh, S. and Choi, S. [2014], 'High gain softswitching bidirectional DC- DC converter for ecofriendly vehicles', IEEE Transactions on Power Electronics 29(4), 1659-1666.

[18] Shukla, A., Verma, K. and Kumar, R. [2018],
'Voltage-dependent modelling of fast charging electric vehicle load considering battery characteristics', IET Electrical Systems in Transportation 8(4), $221-230$.

[19] The Massachusetts Department of Energy Resources [2017], 'Installation Guide for Electric Vehicle Supply Equipment'.

[20] Tulpule, P. J., Marano, V., Yurkovich, S. and Rizzoni, G. [2013], 'Economic and environmental impacts of a $P V$ powered workplace parking garage charging station', Applied Energy 108, 323-332.

[21] Xavier, L. S., Cupertino, A. F. and Pereira, H. A. [2018], 'Ancillary services provided by photovoltaic inverters: Single and three phase control strategies', Computers and Electrical Engineering 70, 102-121. 